\title{
A TEMÁTICA DAS ENTRADAS E BANDEIRAS NOS CURRÍCULOS ESCOLARES
}

Andressa da Silva Gonçalves

Graduada em História pela Universidade Federal do Pará (UFPA). Atualmente realiza o mestrado no programa de pós-graduação em história social da Amazônia (PPHIST/UFPA). A pesquisa em curso se debruça sobre as representações sobre Entradas e Bandeiras nas narrativas didáticas. E-mail:Andressa_g.m@hotmail.com

\section{RESUMO}

Este trabalho tem como finalidade discutir a construção do espaço curricular destinado a temática bandeirante. Desde a proclamação da República a figura bandeirante foi largamente utilizada em discursos oficiais ou de oposição para dar credibilidade através da memória a diversos grupos políticos. Buscamos resgatar tais momentos históricos privilegiados na produção do discurso bandeirista, assim como verificar a presença desta memória criada ao longo do século XX nos currículos estaduais. Percebemos a presença da temática em grande parte dos programas estaduais, inclusive no Pará, revelando a permanência da memória bandeirante, que persiste até nossos dias.

PALAVRAS-CHAVE: Currículo Escolar. Memória. Temática Bandeirante.

\section{THE THEME OF ENTRIES AND FLAGS IN SCHOOL CURRICULUMS}

\begin{abstract}
This work aims to discuss the construction of the curricular space for the theme of pioneering. Since the proclamation of the Republic, the bandeirante figure has been widely used in official or opposition speeches to give credibility through memory to various political groups. We seek to rescue such privileged historical moments in the production of the bandeirista discourse, as well as to verify the presence of this memory created throughout the 20th century in the state
\end{abstract}


curricula. We perceive the presence of the theme in most of the state programs, including in Pará, revealing the permanence of the Bandeirante memory, which persists until today.

KEYWORDS: School curriculum. Memory. Bandeirante Theme.

\section{INTRODUÇÃO}

O currículo escolar hoje em vigor, pode em muitas ocasiões neutro e livre de interferências de interesses específicos, mas, sempre é necessário colocar em pauta que tais prescrições estatais são resultados de demandas e lutas sociais que aconteceram ao longo do tempo e que ainda hoje acontecem. Desta forma, o currículo não é neutro e sim influenciado por um 'jogo dos objetivos’ de grupos sociais que buscam que seus interesses sejam preservados e também sustentados pela prática escolar. A manutenção de uma sociedade de exclusão está na base da construção dos currículos tradicionais ${ }^{1}$ Ivor Goodson (1997), reflete que apenas podemos entender a constituição de um currículo escolar, quando entendemos esse documento como uma pequena parte de um quadro social que demorou séculos para ser construído.

Assim, é necessário apontar que momentos foram fundamentais para a consolidação da memória bandeirante, e consequentemente para sua inclusão no currículo da Educação Básica. Torna-se indispensável também a análise das prescrições estatais para entender a estrutura destas e da inserção da temática bandeirante.

\section{METODOLOGIA}

Para realizar o estudo, acionamos o conceito de representação formulado por Roger Chartier (2002), este ressalta aspectos importantes quanto ao simbolismo e perspectivas que as obras literárias contêm, sendo os autores destas conscientes disso ou não. Este conceito nos permite perceber que o bandeirante foi dotado de diversas roupagens através do tempo, como mostra Pacheco (2011) e cada uma delas atendendo as exigências de determinada sociedade. O conceito de discurso de Mikhail Bakhtin também será essencial na análise, pois tal categoria pressupõe que qualquer fala funde vários juízos, formando uma ampla união de falas. Assim, tal

\footnotetext{
${ }^{1}$ De acordo com Goodson, o currículo tradicional abrange os conhecimentos que são normalmente aceitos, legitimados e reforçados pela comunidade escolar e pela sociedade. Cf. GOODSON, Ivor. Currículo, narrativa e o futuro social. Revista Brasileira de Educação [online]. 2007, vol.12, n.35, pp.241-252.
} 
formulação nos ajudará a perceber os discursos presentes nos currículos, como, por exemplo; a legislação e as formulações acadêmicas. Por último, utilizaremos a definição de cultura histórica de Jacques Le Goff (1996), esta é a percepção de um passado, percepção que pode ser reelaborada e reinterpretada com o passar do tempo. Tal conceito nos ajudará identificar as diversas interpretações que o bandeirante apresenta nas prescrições curriculares.

Nossas fontes, como já citado, serão os currículos estatais. Nosso acervo se constitui pelos documentos de 20 estados, estes são: Amapá, Bahia. Distrito Federal, Espírito Santo, Goiás, Maranhão, Mato Grosso, Mato Grosso do Sul, Minas Gerais, Pará, Paraná, Pernambuco, Piauí, Rio de Janeiro, Rio Grande do Sul, Rondônia, Santa Catarina, São Paulo, Sergipe e Tocantins.

\section{DISCUSSÃO E RESULTADOS}

Percebemos durante o estudo que a imagem do bandeirante foi extremamente utilizada em momentos importantes da história do Brasil. Tal uso da memória ocorria tanto pelo governo oficial, como por grupos contestadores, revelando o uso abrangente desse recurso histórico para legitimar demandas e grupos sociais. Desde a República, a memória bandeirante foi extensivamente evocada, destacamos, a Proclamação da República em que a elite regional paulista resgatou os laços com os antepassados bandeirantes para reivindicar a direção país (FERRETTI, 2004), a Revolução Constitucionalista, em que a memória bandeirante foi mobilizada tanto pelo estado de São Paulo, quanto pelo regime varguista (CAPELATO, 1981). Ressaltamos também o uso da memória bandeirante na Era Vargas, neste período houve uma intensa produção intelectual voltada para associar o movimento bandeirante a marcha para o oeste promovida pelo governo de Vargas (LOSSO, 2008). Salientamos o uso da retórica sertanista na construção de Brasília, neste momento o impulso desbravador bandeirante foi associado a expansão para oeste, simbolizada pela fundação de Brasília (RODRIGUES, 1990).

Por último, a ditadura militar, esta evocou a mitologia bandeirante tanto no impulso desenvolvimentista voltado para a Amazônia, como na adesão de elementos simbólicos bandeirantes na cultura militar (RAHME, 2018). Nestes processos históricos, a memória bandeirante se fez presente para legitimar ideais e principalmente emprestar a essas intenções valores associados aos sertanistas paulistas, entre estes se destaca a vocação desbravadora e civilizadora. 
Com a análise dos currículos escolares, percebemos que o bandeirante continua se fazendo presente nesses documentos, sempre relacionado aos seus feitos, legitimados por uma longa e intencional construção deste símbolo nacional. Apenas quatro estados apresentam nominalmente em seus programas a temática bandeirante e somente dois explicam a função do assunto no aprendizado histórico. Nesse sentido, há uma observação importante a ser feita, apesar de apenas alguns estados citarem diretamente a temática bandeirante, isso não quer dizer que o restante não indique indiretamente o assunto, já que outros tópicos podem também incluir o elemento sertanista, é o caso da expansão territorial colonial e a guerra dos emboabas. Os currículos que citam diretamente a temática são quatro: Amapá, Distrito Federal, Goiás e Minas Gerais. O estado do Amapá em seu programa apresenta vários tópicos sobre o tema bandeirista, embora não explane sobre o objetivo da temática. O distrito Federal também enumera a matéria em seus conteúdos, colocando como objetivo do tema o entendimento da expansão do território brasileiro. O programa de Goiás também acrescenta o sertanismo nos tópicos de conteúdos básicos, mas não explica o objetivo deste. O último estado a elencar o tema é Minas Gerais e coloca como função das Entradas e Bandeiras ressaltar a importância dos bandeirantes para a expansão do território. Percebemos então que dentre os vinte currículos, quatro trabalham diretamente com a temática.

Como dito anteriormente há currículos que trabalham de forma indireta com a questão bandeirante, enumerando assuntos que se relacionam com esta temática. Entre os vinte currículos analisados, dez citam assuntos em que os bandeirantes certamente serão citados, estes estados são: Bahia, Espírito Santo, Maranhão, Mato Grosso do Sul, Pará, Rio de Janeiro, Rondônia, São Paulo, Sergipe e Tocantins. Entre os assuntos que provavelmente farão referência o bandeirante e foram sugeridos nos currículos; temos: Formação e expansão territorial, identidade nacional, mineração, missões jesuíticas, construção de heróis brasileiros e guerra dos emboabas. É importante destacar que mesmo que tais documentos não abordem diretamente a temática das Entradas e Bandeiras, se elencam conteúdos que relacionam-se diretamente com esta e ao serem trabalhados o bandeirante também vai ser um elemento importante da discussão. Portanto, consideramos que tais currículos também disseminem a memória bandeirante.

Alguns currículos analisados não elencaram os conteúdos a serem trabalhados em sala de aula, dispuseram apenas eixos, habilidades e competências. Os estados que escolheram tal 
formato, foram seis: Mato Grosso, Paraná, Pernambuco, Piauí, Rio Grande do Sul e Santa Catarina. Já que os conteúdos não foram detalhados na maioria desses programas, não temos como analisar se a temática bandeirante vai ou não ser ministrada nas escolas. Podemos afirmar, que dos vinte currículos analisados, 16 direta ou indiretamente se remetem ao tema das Entradas e Bandeiras. Portanto há uma considerável inserção deste conteúdo nas escolas, fazendo eco a enorme adesão da temática na literatura didática. Tal temática, como se pode perceber, pode ser encontrada em pontos chaves do período colonial, sendo um tópico que muito dificilmente não será trabalho em algum momento da vida escolar dos estudantes, constatando a persistência de uma memória que ascende ainda no século XIX.

\section{CONSIDERAÇÕES FINAIS}

Neste estudo, destacamos processos históricos em que a memória bandeirante foi amplamente evocada em discursos políticos, em seguida analisamos se a mitologia tão utilizada para legitimar grupos e demandas específicas continua nos currículos escolares, para tanto, analisamos os currículos de vinte estados. Percebemos que a temática sertanista se faz presente nestas prescrições escolares, em tais documentos mesmo que não haja a referência explícita as Entradas e Bandeiras, se enumera conteúdos intimamente relacionados a temática bandeirante, como expansão territorial e a guerra dos emboabas. Logo, a presença desse tema é evidente nas formulações curriculares.

\section{REFERÊNCIAS BIBLIOGRÁFICAS}

\section{FONTES PRIMÁRIAS}

Currículo em Movimento da Educação

Básica: Ensino Fundamental Anos Finais. 2013. (Distrito Federal)

Currículo do Estado de São Paulo: Ciências Humanas e suas tecnologias. 2012. (São Paulo)

Currículo Básico Comum do Ensino Fundamental: História. 2014. (Minas Gerais)

Currículo Básico Escola Estadual. 2009. (Espírito Santo)

Currículo Referência da Rede Estadual de Educação de Goiás. 2012. (Goiás)
Diretrizes Curriculares/Secretaria de Estado da Educação do Maranhão. 2014. (Maranhão)

Diretrizes Curriculares da Educação Básica: História. 2008. (Paraná)

Diretrizes Curriculares da Rede Pública Estadual de Ensino do Piauí, Ensino Fundamental e Ensino Médio. 2013. (Piauí)

Documento curricular do Estado do Pará. Educação infantil e ensino fundamental. 2018. (Pará)

Orientações Curriculares: Área de Ciências Humanas: Educação Básica. 2012. (Mato Grosso) 
Orientações curriculares e subsídios didáticos para a organização do trabalho pedagógico no ensino fundamental de nove anos. 2013. (Bahia)

Orientações Curriculares: Diversidades Educacionais. 2012. (Mato Grosso)

Parâmetros para a Educação Básica do Estado de Pernambuco: Parâmetros Curriculares de História - Ensino Fundamental e Médio. 2013. (Pernambuco)

Plano curricular da educação básica do Estado do Amapá. 2009. (Amapá)

Proposta curricular de Santa Catarina: Estudos Temáticos. 2005. (Santa Catarina)

Proposta curricular de Santa Catarina: formação integral na educação básica. 2014. (Santa Catarina)

Referencial Curricular da Rede Estadual de Ensino de Mato Grosso do Sul: Ensino fundamental. 2012. (Mato Grosso do Sul)

Reorientação curricular - Livro III Ciências Humanas. 2005. (Rio de Janeiro)

Referencial Curricular - Lições do Rio Grande - Ciências Humanas e suas Tecnologias. 2009. (Rio Grande do Sul)

Referencial Curricular de Rondônia Ensino Fundamental. 2013. (Rondônia)

Referencial Curricular: Rede Estadual de Ensino de Sergipe. 2011. (Sergipe)

Referencial Curricular do Ensino Fundamental das escolas públicas do Estado do Tocantins: Ensino Fundamental do $1^{\circ}$ ao $9^{\circ}$ ano. 2009. (Tocantins)

\section{FONTES SECUNDÁRIAS}

BAKHTIN, Mikhail. Marxismo $e$ filosofia da linguagem. Rússia: HUCITEC, 2006.

CAPELATO, Maria Helena. $O$ movimento de 1932. $1^{\circ}$ edição. São Paulo: Brasiliense, 1981.

CHATIER, Roger. A história CulturalEntre práticas e representações. Portugal: DIFEL, 2002.

FERRETI, Danilo José Zioni. A construção da paulistanidade. Identidade, historiografia e política em São Paulo (1856-1930). Tese (Doutorado em história social) Departamento de história, Universidade de São Paulo. São Paulo, 2004.

GOODSON, Ivor. A construção social do currículo. Lisboa: Educa, 1997.

LE GOFF, Jacques. História $e$ Memória. Tradução de Irene Ferreira, Bernardo Leitão e Suzana Ferreira Borges. Campinas, São Paulo: UNICAMP, 1996.

LOSSO, Tiago Bahia. Estado e democracia no discurso oficial do Estado Novo. Política \& Sociedade, v. 7, p. 95-117, 2008.

PACHECO, Manuel. Heróis nos livros didáticos: bandeirantes paulistas. 1. ed. Dourados: Ed. UFGD, 2011.

RAHME, Ana Maria. Configurações Paulistas: operando a saga bandeirante. Revista ARA, v. 5, n. 5, p. 77-108, 2018.

RODRIGUES, Georgete Medleg. Ideologia, propaganda e imaginário social na construção de Brasília (19561960). Dissertação (Mestrado em história) - Instituto de Ciências Humanas, Universidade de Brasília. Brasília, 1990. 
GONÇALVES, A. S. A Temática das Entradas e Bandeiras nos Currículos Escolares. Complexitas Rev. Fil. Tem. Belém, v. 4, n. 1, p. 24-30, jan./jun. 2019. Disponível em: http://www.periodicos.ufpa.br/index.php/complexitas/article/view/8041>. Acesso em: 30 de janeiro de 2020 . 